Supplement of Biogeosciences Discuss., 12, 6037-6080, 2015

http://www.biogeosciences-discuss.net/12/6037/2015/

doi:10.5194/bgd-12-6037-2015-supplement

(C) Author(s) 2015. CC Attribution 3.0 License.

(c) (i)

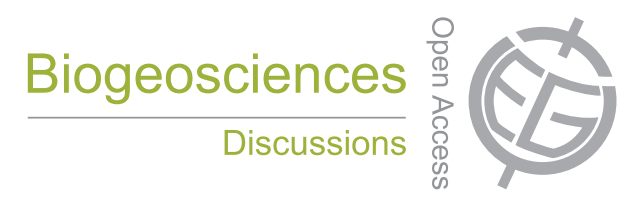

Supplement of

\title{
Probing the past 30 year phenology trend of US deciduous forests
}

X. Yue et al.

Correspondence to: X. Yue (xuyueseas@gmail.com) 


\section{Supporting Information}

\section{Derivation of phenological observations}

One difficulty in analyzing trend of forest phenology is the missing of long-term records. In this study, we derive phenological observations in combination of date records, leaf area index (LAI), and photos. Date records are complete and last for $>20$ years at Harvard Forest and Hubbard Brook. However, the data are incomplete at US-UMB and US-MMS. Budburst dates are documented for 10 years at US-UMB (Fig. S2a). We use the LAI measurements from 1999 to gap fill the missing dates. In this procedure, the budburst dates are defined as the days when the interpolated or extrapolated LAI is equal to a selected threshold (LAIt), which may vary from 0.5 to 2.0. As shown in Fig. S2a, a different LAIt can determine an independent time series. The most reasonable LAIt is determined if the derived time series has the lowest RMSE against the available date records. For example, the RMSE for derived phenology is 5.6 days with LAIt $=1.3 \mathrm{~m}^{2} \mathrm{~m}^{-}$ 2, 3.2 days with $\mathrm{LAIt}=1.5 \mathrm{~m}^{2} \mathrm{~m}^{-2}$, and 4.1 days with $\mathrm{LAIt}=1.7 \mathrm{~m}^{2} \mathrm{~m}^{-2}$. As a result, we select LAIt $=1.5 \mathrm{~m}^{2} \mathrm{~m}^{-2}$ as the standard threshold to derive the missing budburst dates. A similar procedure is performed for US-MMS and a lower LAIt of $1.4 \mathrm{~m}^{2} \mathrm{~m}^{-2}$ is selected for this site (not shown).

In case that the LAI measurements are also incomplete, we derive those missing dates using photos from PhenoCam (http://phenocam.sr.unh.edu/webcam/). Different from the quantitative estimate with LAI, the derivation with photo is qualitative. We define the budburst date as the middle of the few days when tree colors change rapidly from gray to light green. On the contrary, a dormancy start date is defined as the middle of days with rapid color changes from brown to gray. An example of autumn dormancy at US-UMB is shown in Fig. S3. The comparison shows that the photo-derived dates are not largely different from the LAI-derived ones (Fig. S2b). We aggregate all the available dates to develop the most complete dataset for validation (Fig. 1). In case of data overlap from different sources, we select date records as the primary choice and that derived from LAI as the secondary. 

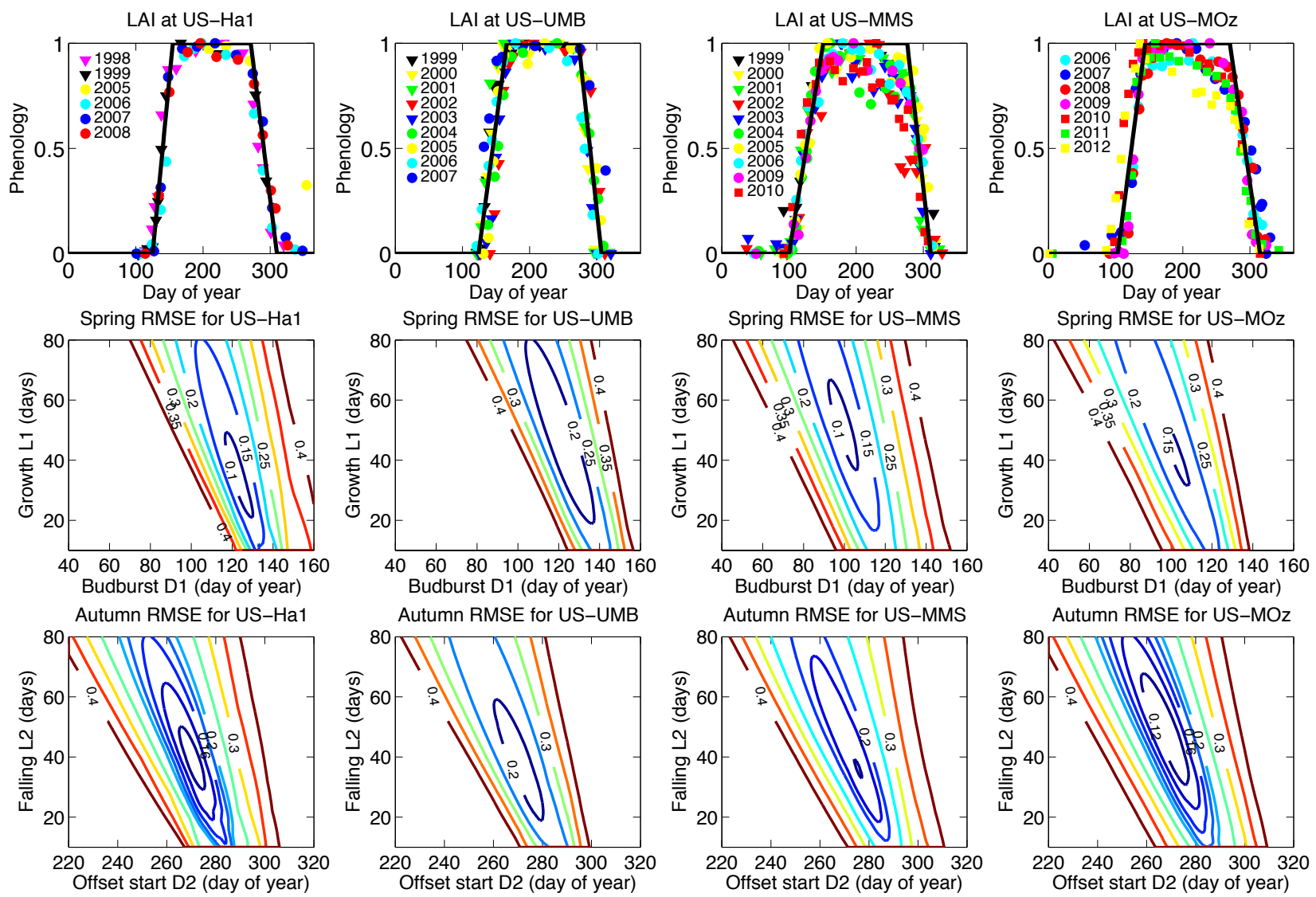

Figure S1. Observed (markers) and regressed (black lines) phenology at four DBF sites (top row). At each site, sensitivity tests of regressions for the $d$ th day of the year are performed with different budburst dates (D1), growing length (L1), offset start dates (D2), and falling length (L2) as follows:

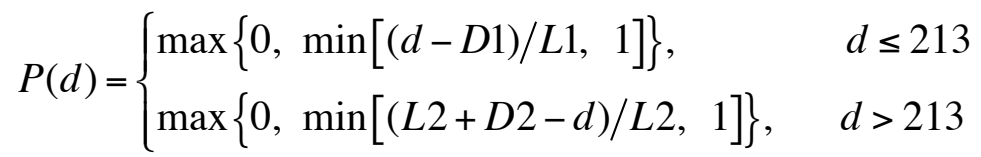

The $213^{\text {th }}$ day of year is correspondent to August $1^{\text {st }}$. Contour maps of the root-meansquare error (RMSE) for these regressions against observations are shown for spring (middle row) and autumn (bottom row). The optimized regressions with specific dates (D1, L1, D2, and L2), which result in a minimum regression RMSE, are shown as the bold lines in the top figures. 
(a) Budburst date at US-UMB

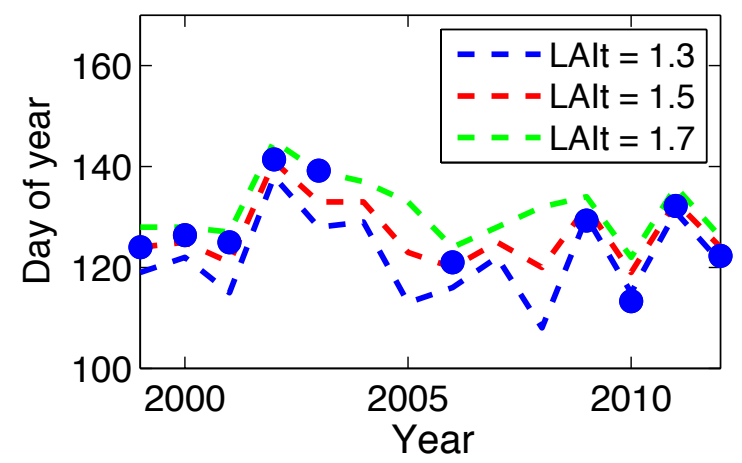

(b) Dormancy start date at US-UMB

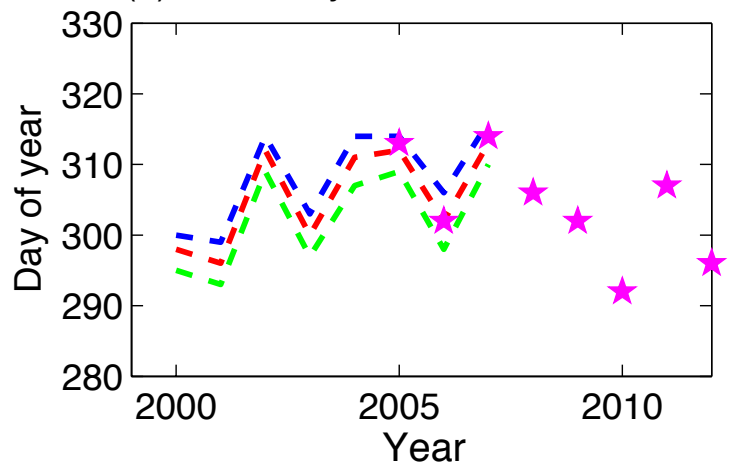

Figure S2. Derived (a) budburst and (b) dormancy state date with different LAI thresholds at site US-UMB. Observations from date records are indicated as blue points. Dates derived from photos (see Fig. S3) are shown as magenta pentagrams. 


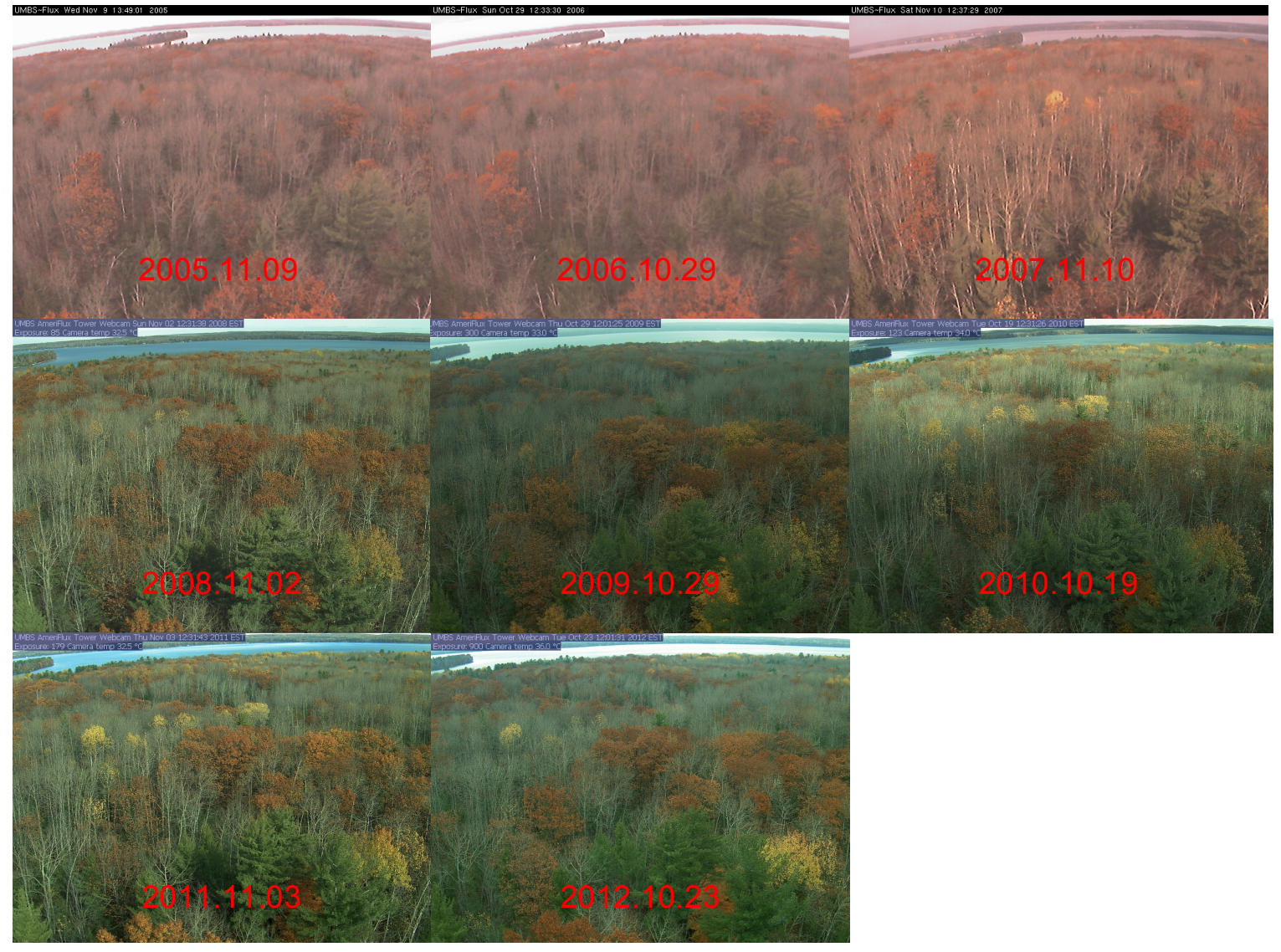

Figure S3. Photos of autumn phenology at US-UMB sites. A dormancy start date is defined as the middle of a few days with rapid color changes from brown to gray The photos after 2008 have better quality relative to earlier years due to an update of equipment. 

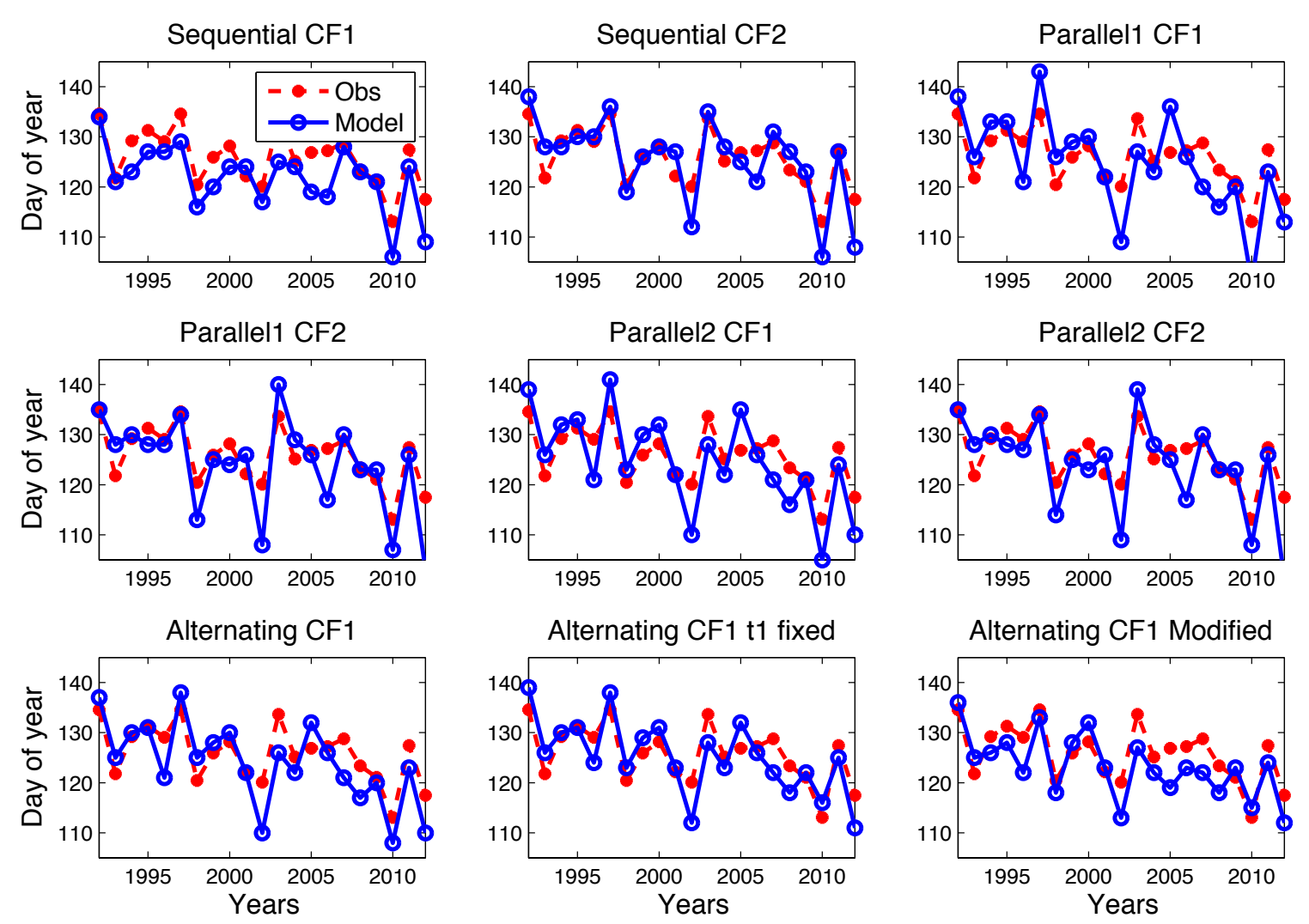

Figure S4. Comparison of predicted (blue) budburst dates at Harvard Forest with observations (red) for 1992-2012. Each panel represents results using a spring phenology model (Table 5). 

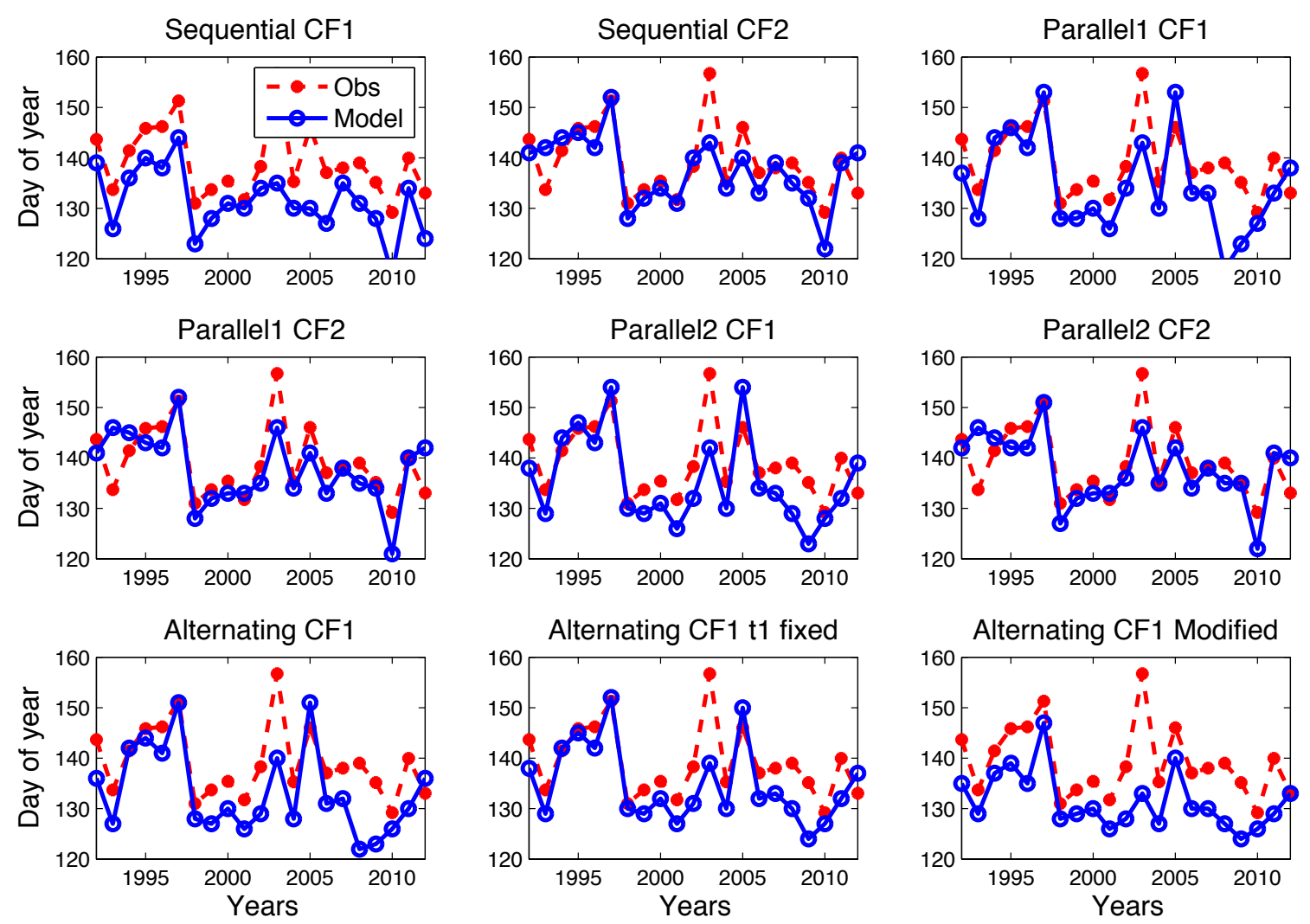

Figure S5. The same as Fig. S4 but for the site at Hubbard Brook. 

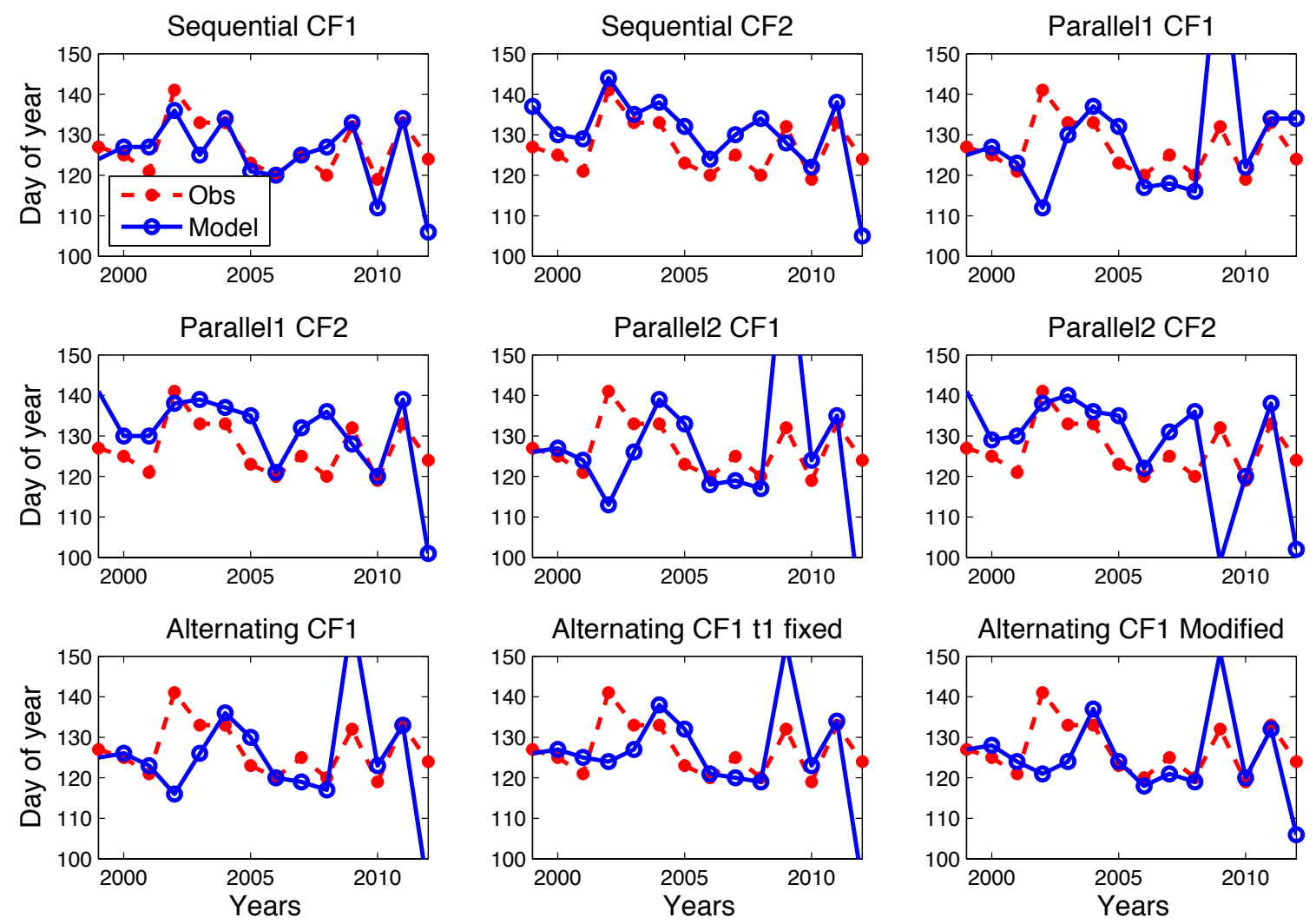

Figure S6. The same as Fig. S4 but for the site at US-UMB for 1999-2012. 

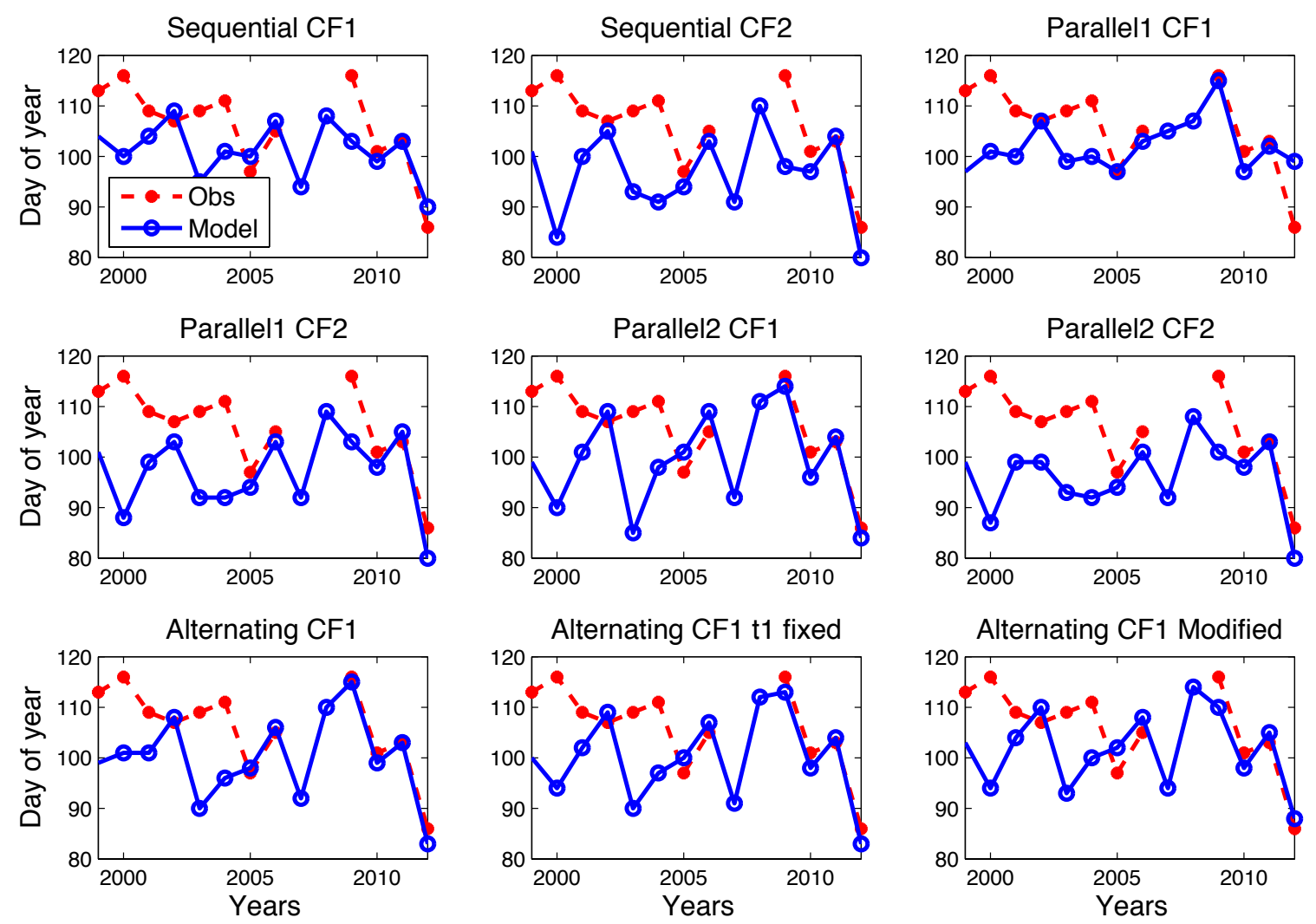

Figure S7. The same as Fig. S4 but for the site at US-MMS for 1999-2012. 

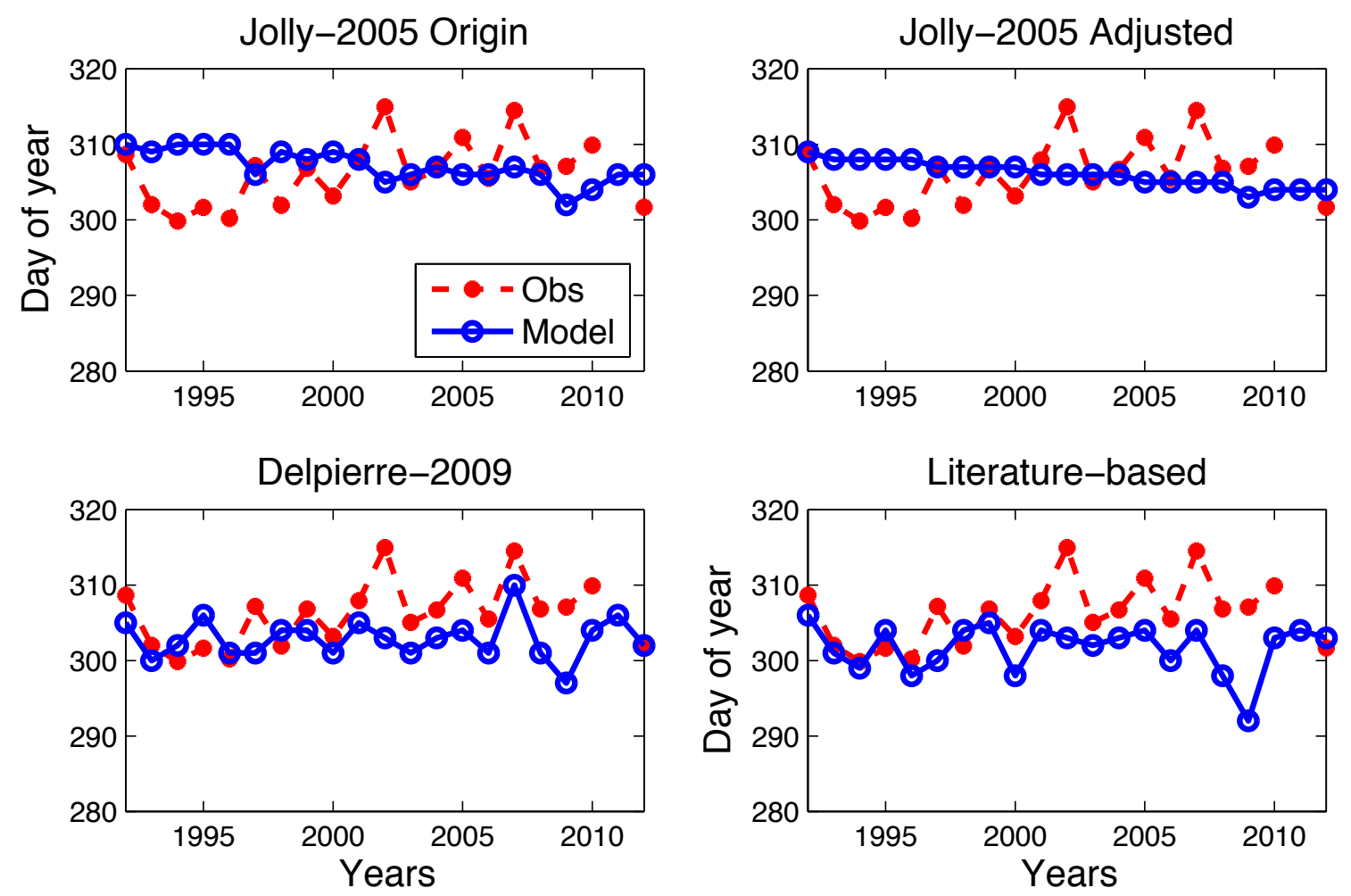

Figure S8. Comparison of predicted (blue) dormancy onset dates at Harvard Forest with observations (red) for 1992-2012. Each panel represents results using an autumn phenology model (Table 5). 

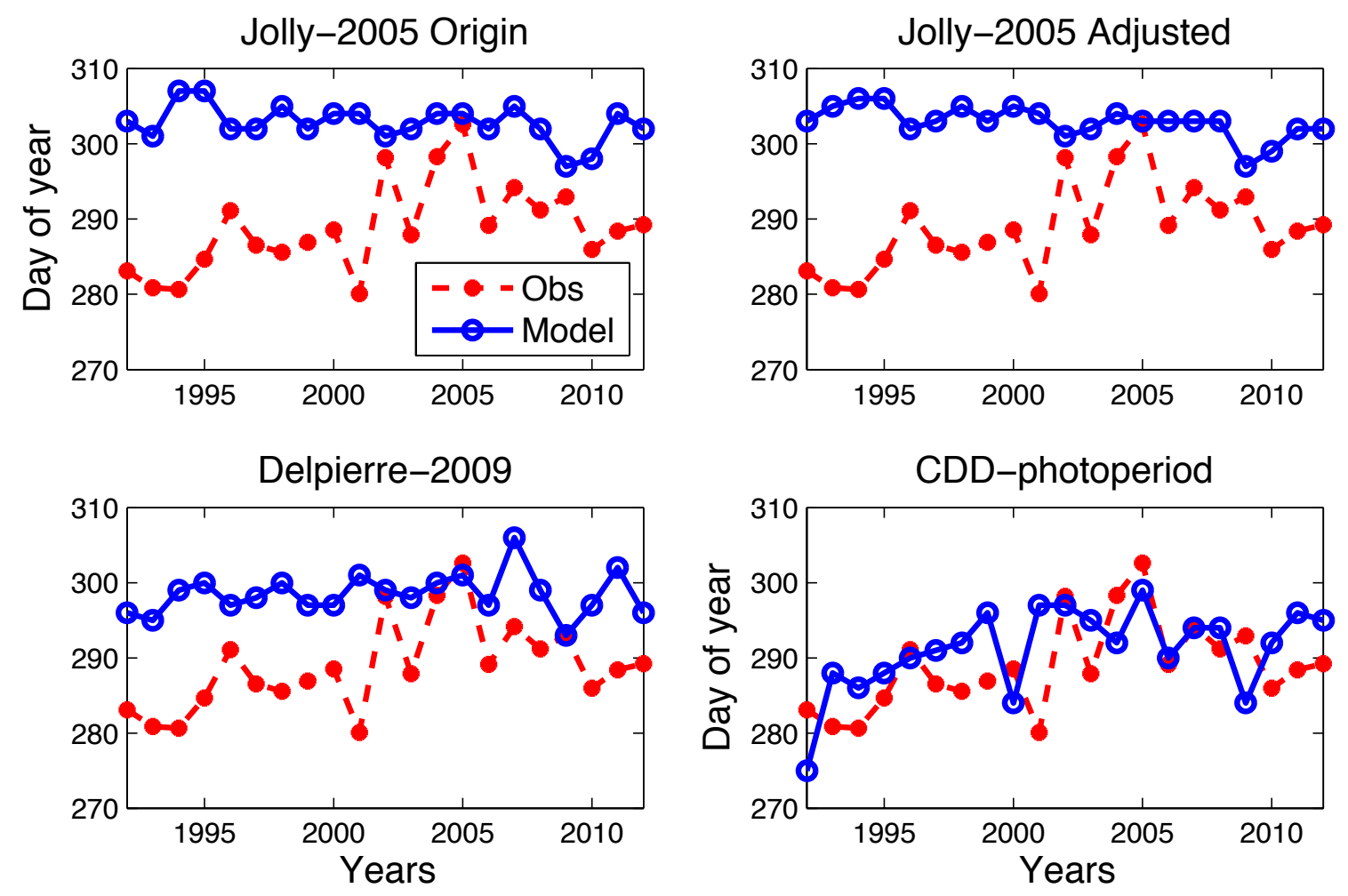

Figure S9. The same as Fig. S8 but for the site at Hubbard Brook. 

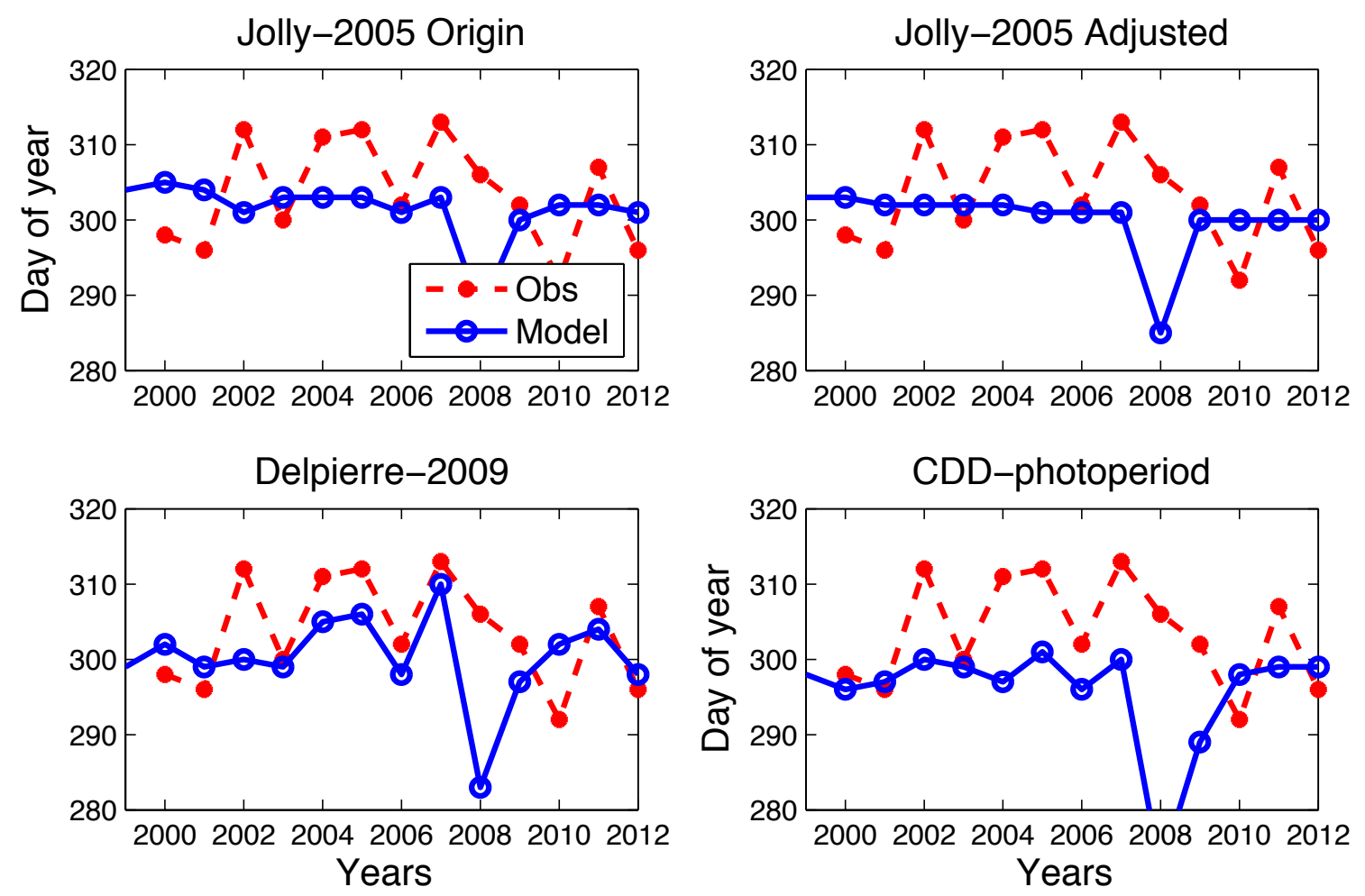

Figure S10. The same as Fig. S8 but for the site at US-UMB for 1999-2012. 

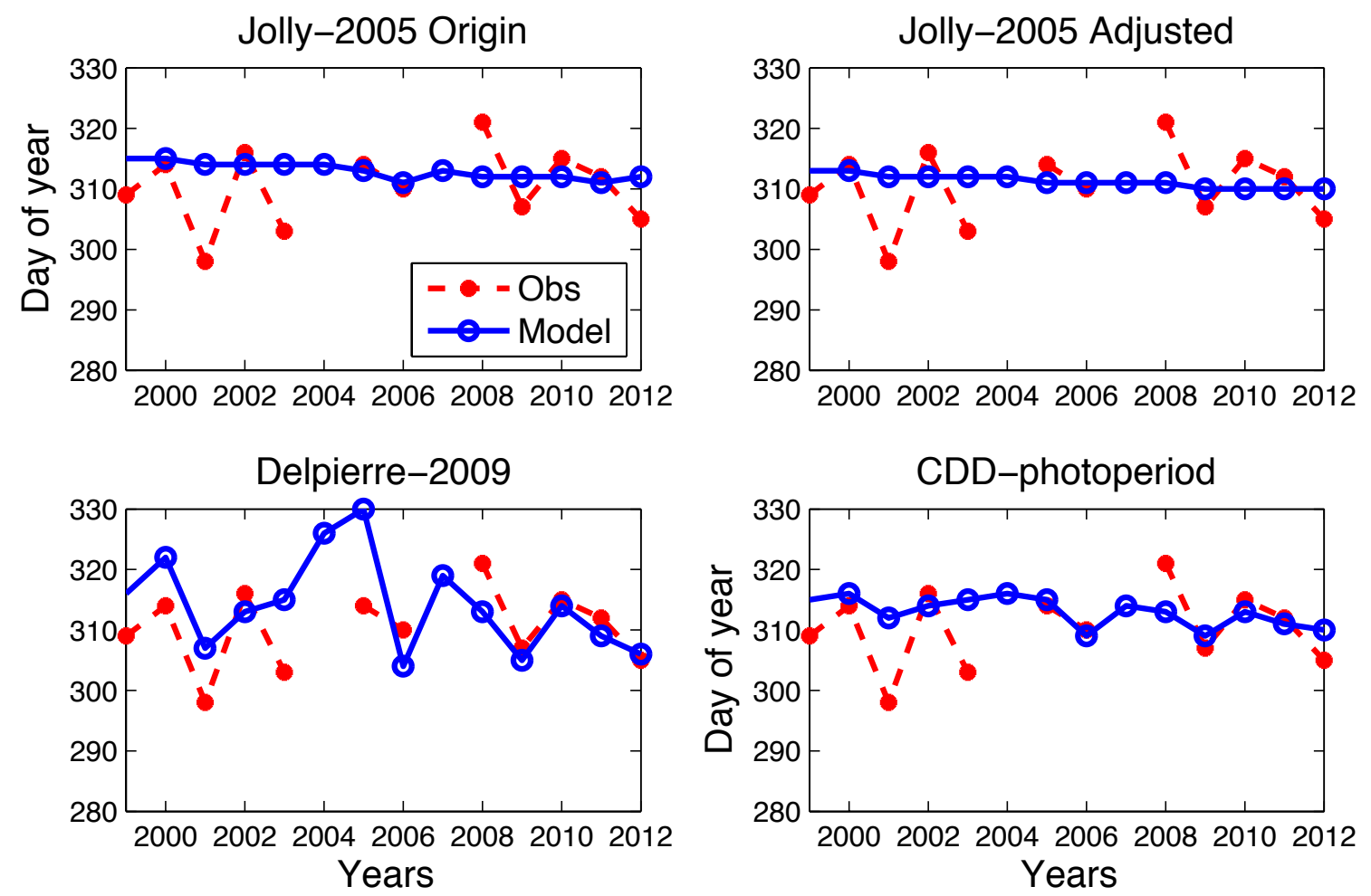

Figure S11. The same as Fig. S8 but for the site at US-MMS for 1999-2012. 
(a) Start of budburst date in 2011

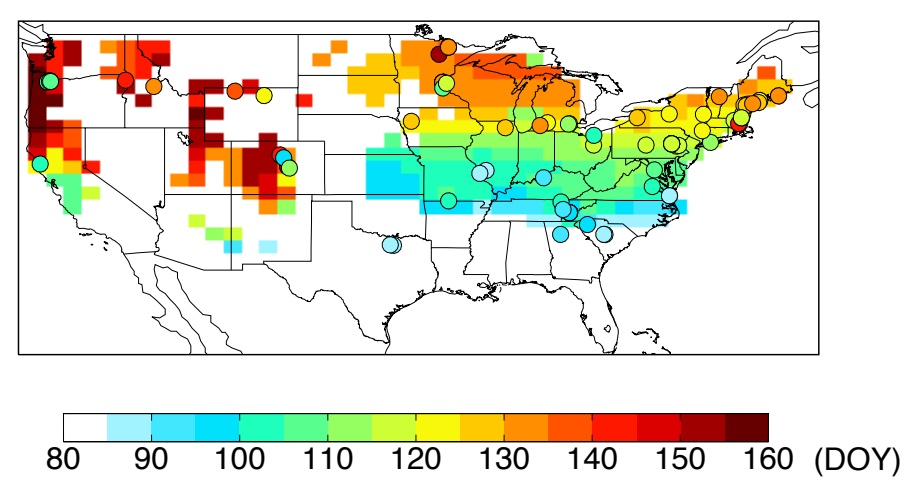

(c) Start of dormancy date in 2011

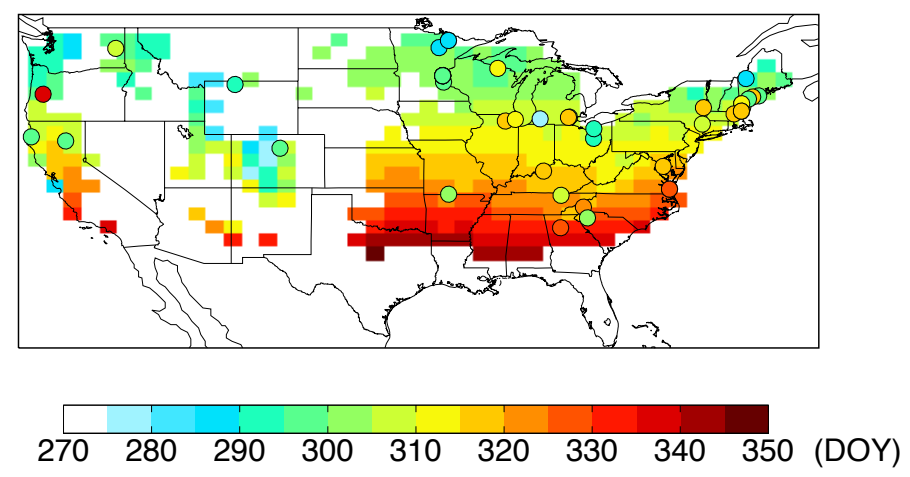

(b) Budburst dates

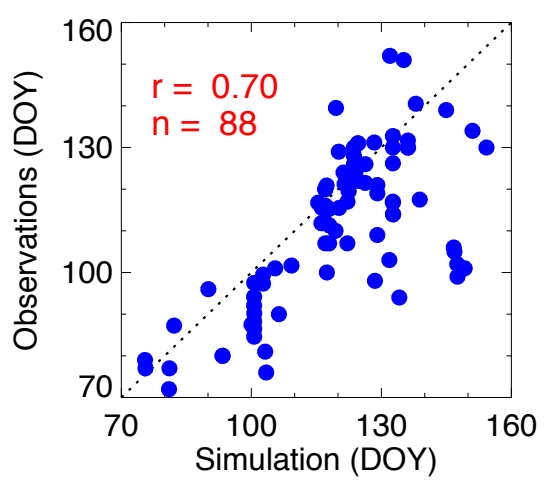

(d) Dormancy dates

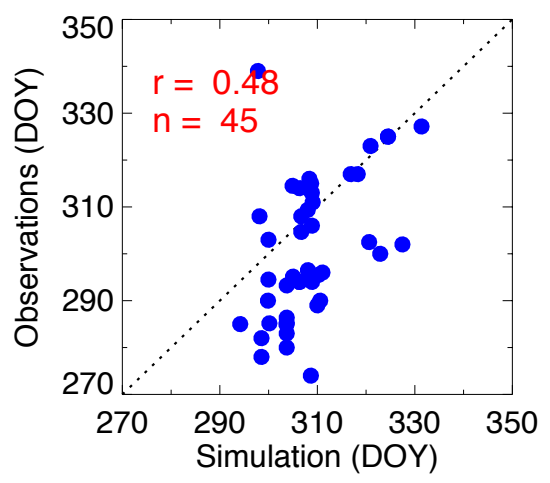

Figure S12. Comparison of the simulated $(a, b)$ budburst and (c, d) dormancy dates with in situ observations (colored circles) from the USA National Phenology Network for 2011. Simulations are performed with the spring model S9 and autumn model A4. The number of the sites and the correlation coefficients are shown in the scatter plots. 
(a) Start of budburst date in 2012
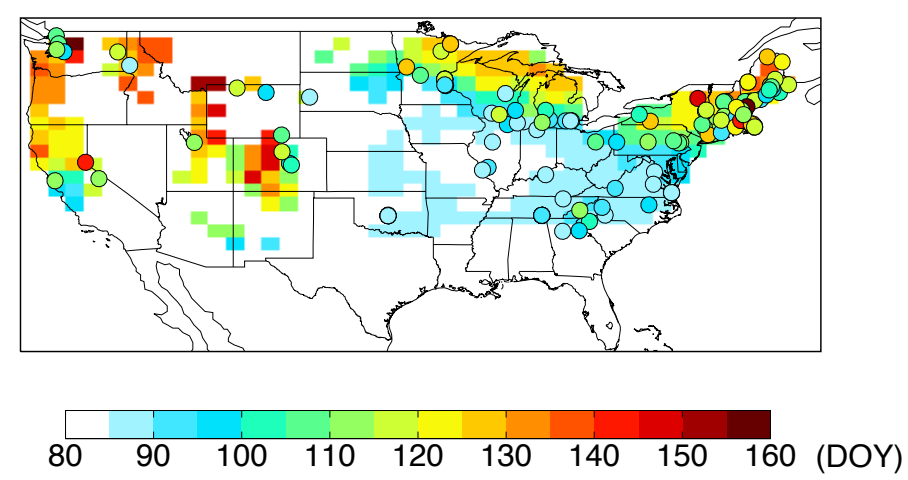

(c) Start of dormancy date in 2012

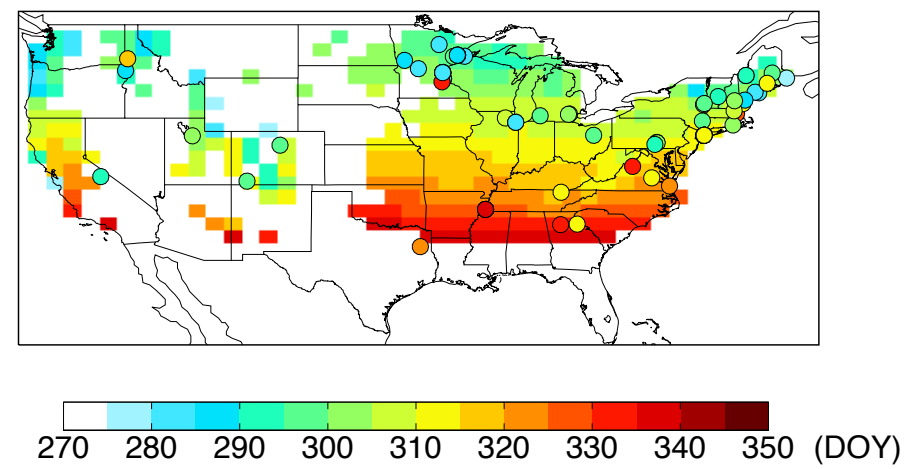

(b) Budburst dates

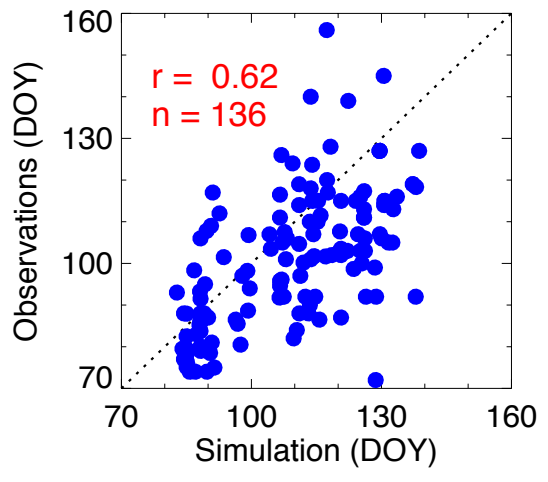

(d) Dormancy dates

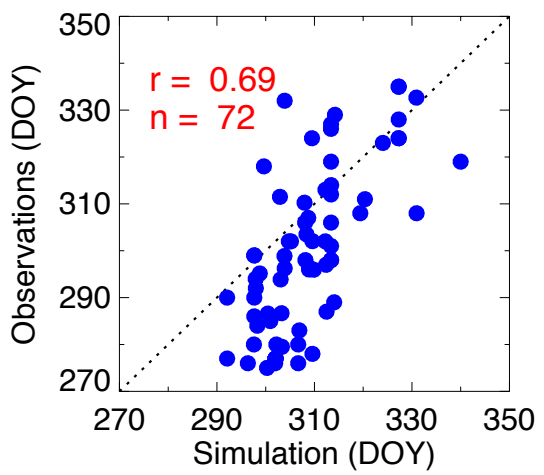

Figure S13. The same as Fig. S12 but for the year 2012. 
(a) budburst $2000-2012$

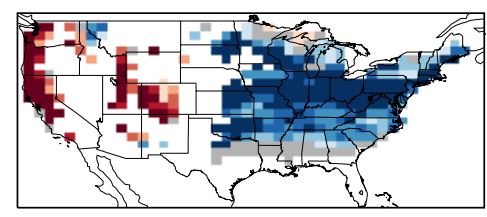

(d) dormancy 2000-2012

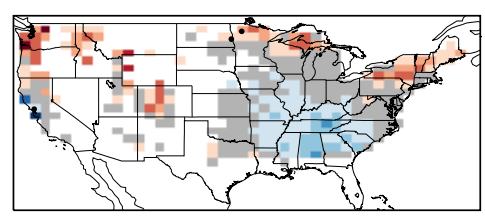

(b) budburst 2000-2011

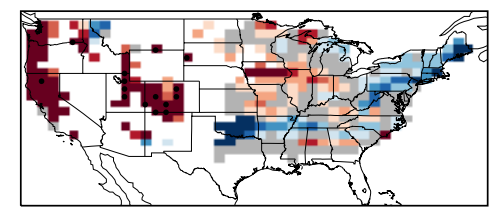

(e) dormancy 2000-2011

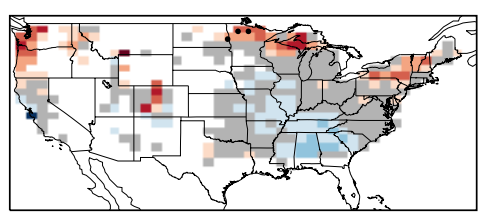

(c) budburst 1982-2011

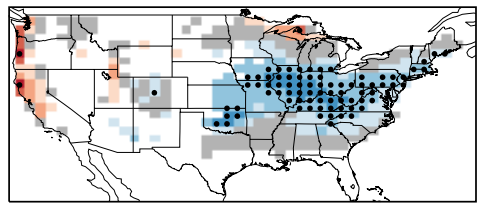

(f) dormancy 1982-2011

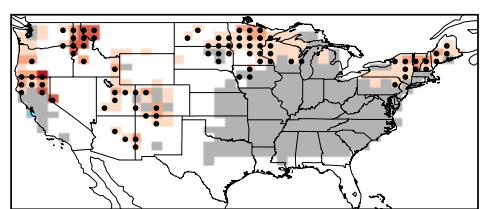

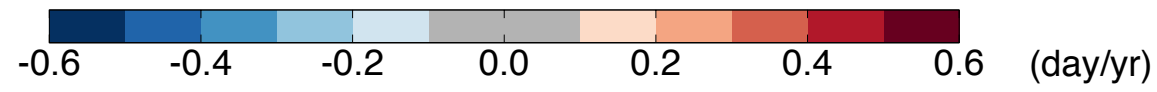

Figure S14. Trend in the simulated (a, b, c) budburst and (d, e, f) dormancy dates for deciduous forests in the U.S. during different periods. Significant trends $(p<0.05)$ are denoted with dots. 
(a) Trend in JAN MERRA TAS

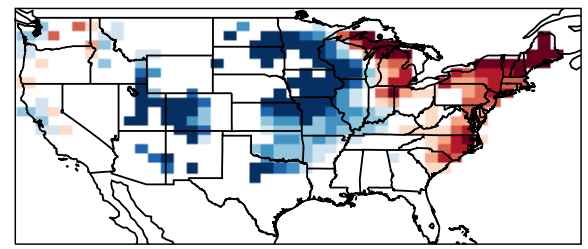

(c) Trend in APR MERRA TAS

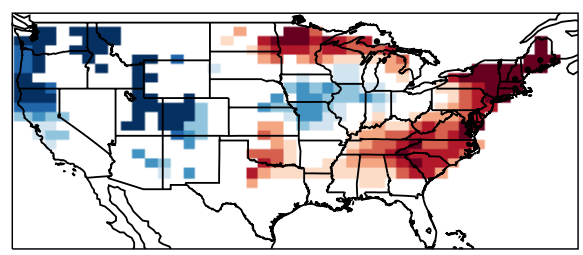

(e) Trend in SEP MERRA TAS

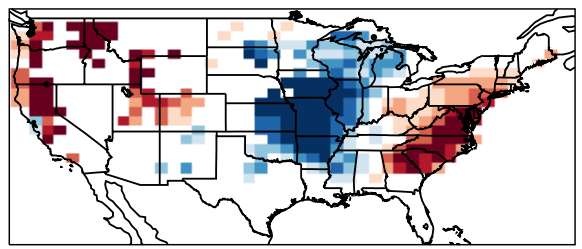

(b) Trend in JAN USHCN TAS

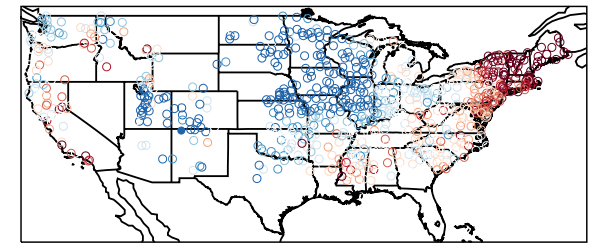

(d) Trend in APR USHCN TAS

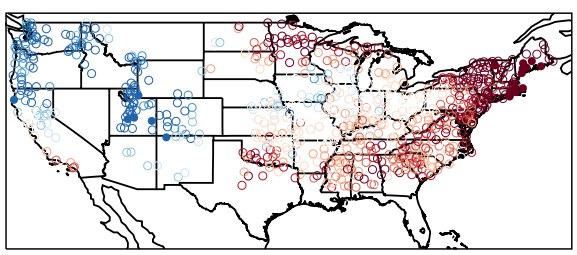

(f) Trend in SEP USHCN TAS

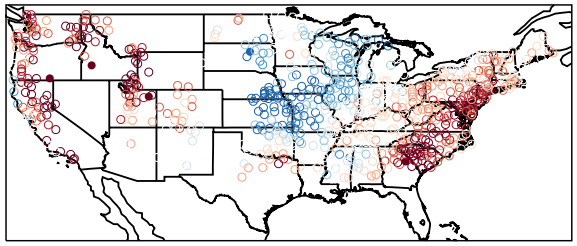

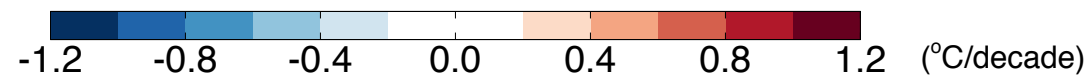

Figure S15. Trend of surface air temperature for (a, b) December, (c, d) April, and (e, f) September during 2000-2012. The temperature data are from (a, c, e) MERRA reanalyses and $(b, d, f)$ USHCN Network. The results are shown only for the grid squares where the fraction of deciduous forest is larger than 3\%. Significant trends are denoted with dots (a, $c, e)$ or solid points $(b, d, f)$. 
(a) Trend in start of budburst date for $1982-2012$

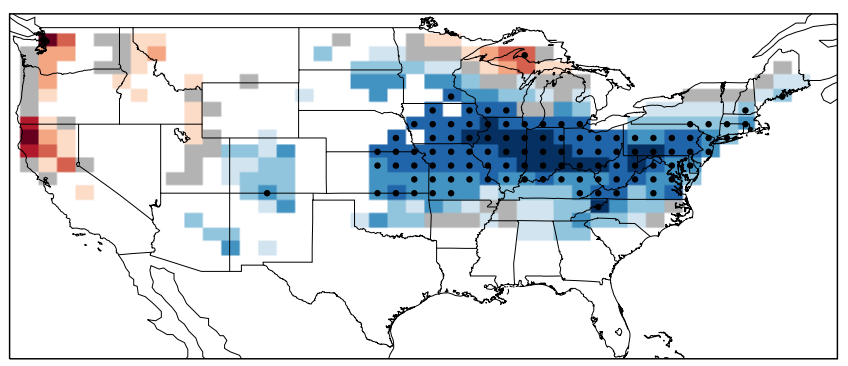

(b) Trend in start of dormancy date for $1982-2012$
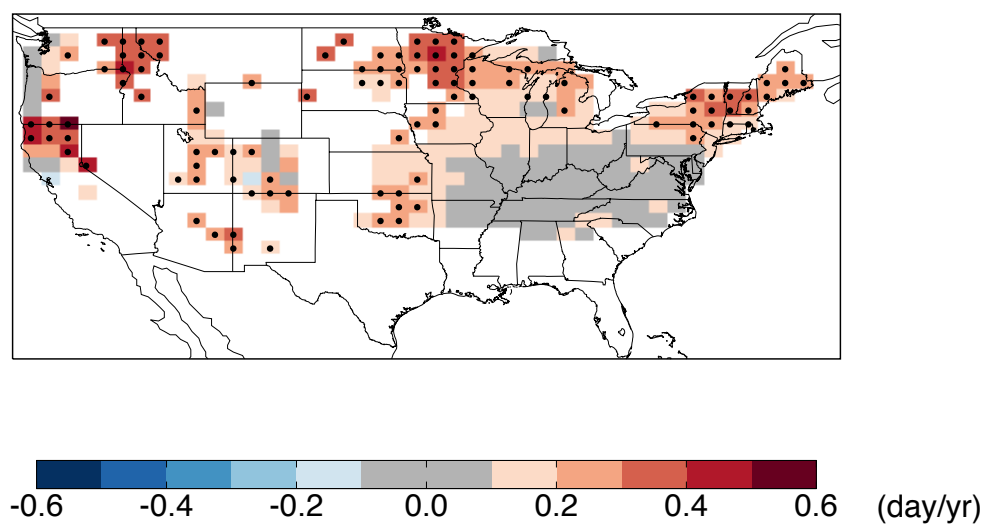

Figure S16. Trend in the simulated (a) budburst and (b) dormancy dates for deciduous forests in the U.S. during 1982-2012 using models without (a) chilling requirement and (b) photoperiod limit. The results are shown only for the grid squares where the fraction of deciduous forest is larger than $3 \%$. Significant trends $(p<0.05)$ are denoted with dots. 
Table S1. Detailed information of phenological records for 52 species from the National Phenology Network during 2011-2012.

\begin{tabular}{|c|c|c|c|c|c|}
\hline Species & Latin Name & Common Name & Sites & Trees & Records \\
\hline ACMA & Acer Macrophyllum & Bigleaf Maple & 26 & 41 & 129 \\
\hline $\mathrm{ACNE}$ & Acer Negundo & Boxelder Maple & 27 & 32 & 685 \\
\hline $\mathrm{ACPE}$ & Acer Pensylvanicum & Striped Maple & 6 & 11 & 42 \\
\hline ACPL & Acer Plantanoides & Norway Maple & 6 & 12 & 160 \\
\hline ACRU & Acer Rubrum & Red Maple & 177 & 306 & 4239 \\
\hline ACSA1 & Acer Saccharinum & Silver Maple & 11 & 14 & 154 \\
\hline ACSA2 & Acer Saccharum & Sugar Maple & 75 & 123 & 1652 \\
\hline AEFL & Aesculus Flava & Yellow Buckeye & 3 & 17 & 327 \\
\hline ALRU & Alnus Rubra & Red Alder & 13 & 14 & 163 \\
\hline AMLA & Amerlanchier Laevis & Serviceberry & 2 & 3 & 58 \\
\hline BEAL & Betula Alleghaniensis & Yellow Birch & 16 & 39 & 301 \\
\hline BELE & Betula Lenta & Sweet Birch & 9 & 13 & 86 \\
\hline BEPA & Betula Papyrifera & Paper Birch & 38 & 63 & 1226 \\
\hline CACA & Carpinus Caroliniana & American Hornbeam & 11 & 40 & 142 \\
\hline CAGL & Carya Glabra & Pignut Hickory & 13 & 28 & 492 \\
\hline CAIL & Carya Illinoinensis & Pecan & 14 & 36 & 217 \\
\hline CAOV & Carya Ovata & Shagbark Hickory & 5 & 7 & 45 \\
\hline CECA & Cercis Canadensis & Redbud & 60 & 94 & 1574 \\
\hline CEOC & Celtis Occidentalis & Hackberry & 11 & 40 & 243 \\
\hline COFL & Cornus Florida & Flowering Dogwood & 85 & 115 & 1193 \\
\hline DIVI & Diospyros Virginiana & Persimmon & 12 & 17 & 262 \\
\hline FAGR & Fagus Grandifolia & American Beech & 37 & 59 & 1458 \\
\hline FRAM & Fraxinus Americana & White Ash & 12 & 16 & 135 \\
\hline FRPE & Fraxinus Pennsylvanica & Green Ash & 20 & 38 & 489 \\
\hline GIBI & Ginkgo Biloba & Ginkgo & 5 & 10 & 81 \\
\hline GLTR & Gleditsia Triacanthos & Honey Locust & 8 & 15 & 101 \\
\hline HAVI & Hamamelis Virginia & Witch Hazel & 17 & 26 & 280 \\
\hline ILVE & Ilex Verticillata & Winterberry & 2 & 3 & 57 \\
\hline JUNI & Juglans Nigra & Black Walnut & 27 & 48 & 579 \\
\hline LIST & Liquidambar Styraciflua & Sweetgum & 33 & 55 & 511 \\
\hline LITU & Liriodendron Tulipifera & Tuliptree & 44 & 89 & 716 \\
\hline NYSY & Nyssa Sylvatica & Black Gum & 9 & 16 & 156 \\
\hline OXAR & Oxydendrum Arboreum & Sourwood & 3 & 5 & 26 \\
\hline PLOC & Platanus Occidentalis & Sycamore & 4 & 5 & 24 \\
\hline PODE & Populus Deltoides & Eastern Cottonwood & 7 & 7 & 54 \\
\hline POTR & Populus Tremuloides & Trembling Aspen & 75 & 135 & 3410 \\
\hline PRAM & Prunus Americana & American Plum & 16 & 16 & 136 \\
\hline PRSE & Prunus Serotina & Black Cherry & 43 & 73 & 1582 \\
\hline QUAL & Quercus Alba & White Oak & 40 & 59 & 1158 \\
\hline
\end{tabular}




\begin{tabular}{lllrrr}
\hline QUMA & Quercus Macrocarpa & Bur Oak & 23 & 38 & 549 \\
QUPA & Quercus Palustris & Pin Oak & 7 & 9 & 33 \\
QURU & Quercus Rubra & Red Oak & 45 & 57 & 1191 \\
QUVE & Quercus Velutina & Black Oak & 5 & 6 & 65 \\
RHCA & Rhamnus Cathartica & Common Buckthorn & 5 & 5 & 121 \\
RHGL & Rhus Glabra & Smooth Sumac & 2 & 2 & 111 \\
ROPS & Robinia Pseudoacacia & Black Locust & 14 & 19 & 362 \\
SAAL & Sassafras Albidum & Sassafras & 5 & 5 & 69 \\
SAPU & Sambucus Pubens & Red Elderberry & 8 & 16 & 781 \\
TIAM & Tilia Americana & American Basswood & 17 & 21 & 553 \\
ULAM & Ulmus Americana & American Elm & 13 & 34 & 236 \\
VACO & Vaccinium Corymbosum & Highbush Blueberry & 12 & 25 & 737 \\
VIAL & Viburnum Alnifolium & Hobblebush & 2 & 4 & 129 \\
\hline
\end{tabular}


Table S2. Detailed information of phenological records for 7 species from the National Phenology Network during 2004-2012.

\begin{tabular}{lllcccc}
\hline Species & Latin Name & Common Name & Trees & Records & Start & End \\
\hline SYCH & Syringa Chinensis & Red Rothomagensis lilac & 68 & 1770 & 2004 & 2012 \\
SYVU & Syringa Vulgaris & Common Lilac & 108 & 1581 & 2004 & 2012 \\
LOTA & Lonicera Tatarica-arnoldred & Arnold Red honeysuckle & 13 & 725 & 2004 & 2012 \\
FOSP & Forsythia Spp & Forsythia & 2 & 38 & 2005 & 2010 \\
COCA & Cornus Canadensis & Bunchberry Dogwood & 1 & 34 & 2006 & 2012 \\
ACRU & Acer Rubrum & Red Maple & 1 & 56 & 2006 & 2012 \\
COFL & Cornus Florida & Flowering Dogwood & 2 & 27 & 2007 & 2012 \\
\hline
\end{tabular}


Table S3. Parameters for the phenology models (S9+A4) selected for the regional simulations.

\begin{tabular}{ccccc}
\hline Variables & Description & Units & Value & Reference \\
\hline$T_{\mathrm{c}}$ & Base temperature for budburst forcing & ${ }^{\circ} \mathrm{C}$ & 5 & Murray et al. (1989) \\
$a$ & Parameters for budburst threshold $G_{b}$ & Degree day & -110 & Calibrated \\
$b$ & Parameters for budburst threshold $G_{b}$ & Degree day & 550 & Calibrated \\
$r$ & Parameters for budburst threshold $G_{b}$ & Dimensionless & -0.01 & Murray et al. (1989) \\
$L_{\mathrm{g}}$ & Growing length constraint & Degree day & 380 & Calibrated \\
$T_{\mathrm{b}}$ & Base temperature for senescence forcing & ${ }^{\circ} \mathrm{C}$ & 20 & Dufrene et al. (2005) \\
$F_{\mathrm{s}}$ & Threshold for leaf fall & Degree day & 140 & Calibrated \\
$L_{\mathrm{f}}$ & Falling length constraint & Degree day & 410 & Calibrated \\
$P_{\mathrm{x}}$ & Daylength threshold for leaf fall & Minutes & 695 & Calibrated \\
$P_{\mathrm{i}}$ & Daylength threshold for full dormancy & Minutes & 585 & Calibrated \\
\hline
\end{tabular}

\section{References}

Dufrene, E., Davi, H., Francois, C., le Maire, G., Le Dantec, V., and Granier, A.: Modelling carbon and water cycles in a beech forest Part I: Model description and uncertainty analysis on modelled NEE, Ecol Model, 185, 407-436, doi:10.1016/J.Ecolmodel.2005.01.004, 2005.

Murray, M. B., Cannell, M. G. R., and Smith, R. I.: Date of Budburst of fifteen Tree Species in Britain Following Climatic Warming, J Appl Ecol, 26, 693-700, doi:10.2307/2404093, 1989. 